\title{
0 programa de formação dos mentores: conceção e planeamento
}

Teresa Leite

\section{Resumo}

Este texto define e enquadra teoricamente as principais finalidades e orientações metodológicas do programa de formação dos mentores que acompanharam os professores em período probatório. 0 referencial de formação dos mentores construiu-se em torno das diferentes dimensões do ato de ensinar. A metodologia de formação organizou-se a partir do conceito de desenvolvimento profissional, considerando o mentor como objeto e sujeito da formação e procurando articular o processo formativo e o trabalho de supervisão desenvolvido pelos mentores, no terreno. As sessões de formação foram planeadas estrategicamente a partir de questões orientadoras às quais se procurou dar resposta através de um conjunto de atividades e materiais. Durante a implementação do período probatório foi produzido pelos intervenientes um conjunto considerável de documentos que foram trabalhados durante a formação. Palavras-chave: Formação de professores. Desenvolvimento profissional. Supervisão. Dimensões do ensino.

\section{The program's training for mentors: conception and planning}

\section{Abstract}

This article defines and frames theoretically the main purposes and the methodological guidelines of the training program of mentors who have accompanied teachers on the probationary period. Those guidelines were constructed around the different dimensions of the act of teaching. The training methodology was organized from the concept of professional development, considering the mentor as object and subject of training and seeking to articulate the formative process and supervision work developed by mentors on the field. Training sessions have been strategically planned from guiding questions which sought to respond through a range of activities and materials. During the implementation of the probationary period, the participants delivered a considerable set of documents, which were worked on during training. Keywords: Teachers'education. Professional development. Supervision. Teaching dimensions.

* Pós-Doutorado em Ciências da Educação, Escola Superior de Educação de Lisboa; Professora e Investigadora na Escola Superior de Educação do Instituto Politécnico de Lisboa. Email: teresal@eselx.ipl.pt 


\section{El programa de formación de los mentores: concepción y planificación \\ Resumen}

Este texto define y enfoca teóricamente las principales finalidades y orientaciones metodológicas del programa de formación de los mentores que acompañaron a los profesores en el periodo probatorio. La referencia formativa de los mentores se construyó en torno de las distintas dimensiones del hecho de enseñar. La metodología formativa se organizó a partir del concepto de desarrollo profesional, considerando al mentor como objeto y sujeto de la formación y buscando articular el proceso formativo y el trabajo de supervisión desarrollado por los mentores, en el terreno. Las sesiones de formación se proyectaron estratégicamente a partir de planteos orientadores, a los cuales se les dio respuesta a través de un conjunto de actividades y materiales. Durante la implementación del periodo probatorio, los participantes produjeron un considerable conjunto de documentos que se elaboraron durante la formación. Palabras-clave: Formación docente. Desarrollo profesional. Supervisión. Dimensiones de la enseñanza.

\section{Âmbito e finalidade do programa de formação}

0 Programa de Supervisão, Acompanhamento e Avaliação do Periodo Probatório de Professores previa o acompanhamento do processo de supervisão nas escolas mediante sessões de trabalho e formação para os intervenientes, a realizar ao longo do ano.

Optou-se por organizar o processo de formação com os 85 Professores Mentores que, nas escolas, acompanhavam e apoiavam os seus pares em período probatório nos planos didático, pedagógico e científico. Os mentores, por sua vez, levariam para as escolas os processos e os materiais da formação, trabalhando-os com os professores em periodo probatório que acompanhavam.

A formação organizada para os professores mentores visava assim, em última instância, ao desenvolvimento profissional dos professores em Periodo Probatório, procurando contribuir para a melhoria das práticas quer em contexto de sala de aula, quer no âmbito da participação nas dinâmicas organizacionais da escola e da relação com a comunidade educativa.

Por outro lado, ao optar por um trabalho continuado de apoio e acompanhamento aos mentores, a formação visava diretamente ao desenvolvimento profissional destes, através da aquisição de competências de supervisão e através do questionamento e aprofundamento conjunto com o professor em periodo probatório das dimensões analíticas da ação de ensinar. 
A formação foi realizada através da modalidade de Oficina, com a carga horária de cinquenta horas (vinte e cinco de trabalho presencial), intitulada Período Probatório e Desenvolvimento Profissional Docente: Desempenho, Supervisão e Avaliação. As vinte e cinco horas de formação presencial foram distribuídas por 6 sessões. A primeira sessão consistiu num seminário intitulado " $1{ }^{\circ}$ Seminário Nacional Periodo Probatório e Desenvolvimento Profissional Docente", no qual se apresentaram as linhas orientadoras do plano de supervisão, acompanhamento e avaliação do Período Probatório e do respetivo programa de formação de mentores. As conferências integradas nesse seminário pretenderam esclarecer conceitos e modelos de indução profissional e período probatório.

Considerando a dispersão geográfica das escolas envolvidas no período probatório, as restantes sessões da Oficina de Formação foram realizadas simultaneamente em cinco regiões do país: Aveiro, Braga, Évora, Faro e Lisboa. No final da oficina de formação e do primeiro ano do programa do Período Probatório, realizou-se um outro seminário, que teve como objetivo a disseminação, reflexão e debate sobre o processo desenvolvido e no qual se apresentaram comunicações e posters relativos ao trabalho realizado, bem como o balanço do projeto a partir dos resultados da avaliação da formação e dos resultados de questionários sobre o período probatório.

\section{0 referencial do programa de formação dos mentores}

Um mentor é, geralmente, um docente mais experiente que acompanha o professor em início de carreira e o ajuda a inserir-se na cultura da escola. Neste sentido, o mentor apoia o processo de socialização de um professor mais novo, entendendose por socialização profissional do professor a adoção de uma "estratégia social" própria, constituída por uma seleção intencional de ideias e formas de agir face às situações complexas que a profissão coloca (LACEY, 1977 apud SILVA, 1997 p. 55). Esta definição de socialização dos professores em início de carreira remete-nos, definitivamente, para a noção de profissionalidade docente.

Em 1980, Hoyle (1980) definia profissionalidade como "a atitude para com a prática profissional entre os membros de uma ocupação e o grau de conhecimento e competências que proporcionam". Numa perspetiva mais descritiva, Gimeno Sácristán (1991) define o conceito de profissionalidade docente como a "afirmação do que é específico na ação docente, isto é, o conjunto de comportamentos, conhecimentos, destrezas, atitudes e valores que constituem a especifidade de ser professor".

A partir destas duas definições, Contreras Domingo (2003) define profissionalidade docente como "as qualidades da prática profissional dos professores em função do que requer o chamado ofício educativo", conjugando o desempenho profissional com os valores e aspirações desejáveis na profissão. 0 autor sublinha, no entanto, que essas qualidades não são confundiveis com as características do "bom ensino", mas antes "dimensões do fazer profissional no qual se definem aspirações relativamente à forma 
de conceber e viver o oficio docente e, ao mesmo tempo, dimensões nas quais se inscreveria a forma de dotar a realização do ensino de um conteúdo concreto e específico", conteúdo que não surge definitivamente estabelecido, uma vez que é interpretado de forma diferente consoante os contextos e situações. Essas interpretações estão, por isso, marcadas quer pelas crenças sobre o ensino e as suas finalidades, quer pelas condições e exigências concretas das situações, quer ainda pelas formas através das quais os professores vivem e constroem a atividade profissional. Neste sentido, os professores "são simultaneamente veículos através dos quais se concretizam as influências que geram

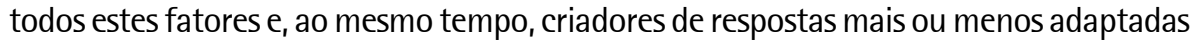
ou críticas a esses mesmos fatores" (CONTRERAS DOMING0, 2003).

0 autor conclui que a maior contribuição do conceito de profissionalidade é a de propor um quadro de preocupações fundamentais para o desenvolvimento da prática educativa e das possiveis dimensões da profissão, entre as quais destaca a obrigação moral, o compromisso com a comunidade e a competência profissional.

Esta última tem sido objeto de múltiplas reflexões e estudos, variando a sua definição de acordo com as conceções de docência e de professor que orientam cada autor. Em jeito de síntese, é possivel considerar três grandes perspetivas sobre a função docente:

- se a docência é encarada como ocupação laboral definida em função de competências necessárias a um posto de trabalho, num quadro definido pelo Estado (e, na maior parte das vezes, tendo o Estado como empregador), então o professor é essencialmente um técnico que, com maior ou menor poder de decisão consoante as políticas nacionais para o setor, põe em prática as orientações que lhe são transmitidas;

- se a docência é perspetivada como profissão (na aceção sociológica do termo), implicando o monopólio de um saber que Ihe é específico, o controle do exercício da profissão e influência sobre a formação, então o professor tem autonomia e responsabilidade para intervir não apenas na sua área de atuação específica, mas também na orientação da atividade profissional e na definição da própria profissão;

- se a docência é considerada uma arte, baseada num saber prático que não é totalmente passivel de teorização, uma vez que grande parte do desempenho em situação fica aquém daquilo que a investigação pode captar e interpretar, então o professor é um artesão que aprende o seu ofício através da observação e da experiência.

Diversos autores defendem hoje que o ensino é uma arte e uma ciência, já que envolve um corpo de conhecimentos consistente e um conjunto de competências complexas, que se interligam com valores e ideologias, com investimento afetivo e capacidades relacionais e que, em situação, exige tomadas de decisão únicas (BROWN; MCINTIRE, 1993; HARGREAVES, 1993; WOODS, 1999). Como afirma Woods (1999): 
"aquilo que é claro é o facto de o ensino ser uma atividade complexa que desafia qualquer tentativa monolítica de caracterização (...) A divisão entre ciência e arte é, de certa forma, artificial (...) tanto a ciência como a arte se baseiam no mesmo tipo de imaginação criativa. Quando se separa a arte da ciência, esta perde o seu estímulo criativo. Igualmente quando a ciência se separa da educação, os professores sacrificam todo um conjunto de conhecimentos adquiridos de uma forma rigorosa. Isto revela a insensatez de debater se o ensino é uma ciência ou uma arte - tal como a maioria das dicotomias e do pensamento polarizado".

No entanto, a harmonização entre estas duas conceções não é pacífica, como resulta evidente nos estudos relativos ao tipo de conhecimentos de que o professor é detentor e ao uso que deles faz na sala de aula e na escola. Autores como Shulman (1992), embora alertem para a natureza essencialmente circunstancial e prática em que o conhecimento dos professores irá ser usado, defendem uma perspetiva do ensino como ciência; enquanto autores como Tom (1988 apud WOODS, 1999) defendem que as orientações educativas baseadas nos resultados da investigação não preparam os professores para o tipo de desempenho flexível que a imprevisibilidade das situações educativas requer e para os quais contribuem sobretudo os saberes aprendidos em ação.

Talvez o cerne da questão da profissionalidade docente não resida na distinção entre ensino como ciência/como arte ou entre ocupação/profissão, mas na compreensão e definição da "especificidade da docência e da relação profissional professor-aluno e na determinação das características constantes dos professores como corpo profissional" (Carrolo, 1997) e, neste sentido, no conhecimento que é necessário deter para o exercício dessa função específica. Com efeito, "o conhecimento socialmente requerido para o desenvolvimento da atividade - no caso em apreço, a docência - constitui um elemento central da afirmação da profissionalidade (...)" (ROLDÃO, 2010a).

0 conhecimento profissional docente é compósito abarcando o conhecimento do conteúdo, o conhecimento relativo ao lugar e finalidade desse conteúdo no currículo, o conhecimento da didática desse conteúdo, o conhecimento do aluno, o conhecimento pedagógico que permite delinear uma estratégia de ação com vista à aprendizagem, o conhecimento reflexivo que permite analisar e reorientar a ação desenvolvida (ROLDÃO, 2010b).

Neste projeto, partimos do princípio que a especificidade da docência é, como afirma Roldão, o ato de ensinar, entendendo-se este como "a ação intencional, sustentada por um saber específico, que consiste em fazer aprender alguma coisa a alguém" (ROLDÃO, 1998). Esse saber específico constitui o conhecimento profissional do professor e requer a articulação e uso integrado das dimensões da profissionalidade anteriormente referidas. 
Mas a atividade docente é, antes de mais, intencional e orientada para finalidades, as quais "proporcionam a estrutura organizadora de todas as decisões que 0 professor toma" (DANIELSON, 2010). É este caráter deliberativo da ação de ensinar que marca uma renovada conceção de profissionalidade docente, estreitamente relacionada com o papel do professor enquanto agente de desenvolvimento curricular. Como sugere Sousa (2010 p. 115), "a deliberação é o método, por excelência, das decisões curriculares". 0 autor afirma ainda:

"A racionalidade deliberativa é, por definição, não burocrática, pois é motivada por um interesse prático e, como tal, sustenta decisões tomadas em função do que, em cada situação concreta, for julgado mais favorável [...], rejeitando a subordinação acrítica a normas pré-definidas e supostamente aplicáveis a qualquer contexto." (Sousa, 2010 p. 118).

Apesar da sua complexidade e multidimensionalidade, o ato de ensinar, como qualquer ato profissional, é decomponivel e analisável. A análise das diferentes dimensões deste ato (conceção, operacionalização, avaliação e reorientação) constituiu o referente principal do programa de formação dos mentores. Neste sentido, a formação foi orientada, desde o início, para o apoio e acompanhamento dos professores em Período Probatório nas diferentes dimensões do ato de ensino.

Em consequência, o plano de formação incidiu sobre: 1) Construção de planos individuais de trabalho e a relação destes com o desenvolvimento profissional; 2) Conceção e planeamento da ação de ensinar; 3) Análise e discussão de situações de docência; 4) Avaliação e regulação do desempenho profissional; 5) Construção de registos e relatórios nos processos de supervisão e avaliação.

\section{0 papel do professor mentor no processo de formação}

A mentoria constitui-se como um processo interativo e dinâmico entre dois docentes que se encontram em diferentes estádios da carreira (CARRUTHERS, 1993, apud KILLEVY; MURPHY, 2006). Para uma mentoria bem sucedida, é necessário que os professores mentores demonstrem capacidades de diálogo, colaboração e negociação interpares e que sejam reconhecidos como profissionais experientes, não apenas ao nivel do conhecimento disciplinar e didático, mas também nos processos de planificação, gestão do grupo e avaliação. Porém, como afirma Marcelo García (1999 p. 127), "a componente crucial é a capacidade para trabalhar em conjunto, alicerçada na confiança mútua, no respeito e na crença de que cada um é capaz de se aperfeiçoar de forma competente".

0 programa de formação de mentores foi portanto concebido para um grupo de professores experientes, empenhados profissionalmente e reconhecidos pelos seus pares como profissionais responsáveis e competentes. Com efeito, estes professores 
encontravam-se já em fases adiantadas da carreira docente, correspondendo àquelas que alguns autores consideram como de mestria ou mesmo já de estabilidade (FULLER; BROWN, 1975; GONÇALVES, 1999; HUBERMAN, 1999).

Neste sentido, a formação visou à exploração e ao aprofundamento de competências pré-existentes, organizando-se a partir dos conhecimentos, atitudes e capacidades que os mentores foram construindo durante o seu percurso profissional e que traziam para a situação de formação. Procurou-se, assim, que a oficina de formação se constituísse como um momento-chave para a consciencialização dessas competências, facilitando simultaneamente a sua mobilização para uma nova situação: a mentoria dos professores em periodo probatório.

Assim equacionada, a formação dos professores mentores enquadrou-se numa perspetiva marcadamente desenvolvimentista1 (MALGLAIVE, 1997; DAY, 2001), procurando-se acentuar o caráter permanente da aprendizagem profissional, mas também a implicação pessoal e coletiva dos formandos-mentores neste processo. Por outro lado, a mentoria e os processos de supervisão a ela ligados, constituiam um novo desafio para estes docentes, pelo quais a formação deveria assumir também uma dimensão de resposta a novas situações, numa perspetiva de resolução de problemas (ERAUT, 1985; MARCELO GARCÍA, 1999).

Tendo em conta a fase da carreira em que estes professores se encontravam e as perspetivas de formação contínua acima mencionadas, o papel do formandomentor no processo de formação foi uma das preocupações centrais na elaboração e desenvolvimento do programa formativo.

A constatação de que, em última análise, é na pessoa do professor em formação e na forma como ele pensa e desenvolve a profissão docente que radica o cerne da profissionalidade e de qualquer possibilidade de desenvolvimento profissional, conduz inevitavelmente à indagação sobre o papel que lhe atribuímos no processo de formação.

Torna-se assim necessário revisitar as tipologias clássicas dos modelos de formação de professores (FERRY, 1987; ZEICHNER, 1983; 1993; MARCELO GARCÍA, 1999), utilizando como critério de análise o papel atribuido ao formando no processo formativo. Estrela (2002) propõe uma tipologia dos modelos de formação de acordo com o papel que o formando assume no processo formativo: como objeto de formação; como sujeito da formação; como objeto e sujeito da formação.

Na primeira categoria, agrupam-se todas as orientações da formação que, numa visão racionalista e normativa do ensino, se baseiam na definição prévia das aquisições a realizar. A segunda categoria engloba os modelos que, baseados no construtivismo, 
se centram na subjetividade do formando e no seu desenvolvimento, favorecendo a descoberta de si próprio enquanto pessoa e enquanto profissional, a descoberta dos outros e da relação que com eles estabelece e ainda a descoberta dos processos mais adequados para a resolução dos problemas que as situações de ensino colocam. $\mathrm{Na}$ terceira categoria, privilegia-se o desenvolvimento de uma atitude de análise e questionamento por parte dos formandos, quer como consumidores de resultados da investigação realizada por outros, quer como participantes em situações de problematização e de pesquisa sobre o real e sobre as consequências sociais e éticas das situações de ensino. Os problemas identificados irão ser objeto de análise, favorecendo a articulação entre teoria-prática e proporcionando uma tomada de consciência crítica, a qual, no contexto da formação, assumindo uma dimensão coletiva e de desenvolvimento da profissionalidade docente, já que pode contribuir para a construção do conhecimento profissional a partir do interior das situações educativas, construção essa realizada de forma sistemática e fundamentada (ESTRELA, 2002).

Entre outros aspetos, a categorização a partir deste critério tem a mais-valia de chamar a atenção para a necessidade de examinar a coerência entre os princípios enunciados num determinado programa de formação e o modo como, efetivamente, o formando é encarado na elaboração, desenvolvimento e avaliação do processo formativo - ao nivel das atividades formativas e, sobretudo, a nivel da prática pedagógica e da maneira como esta se articula com a teoria, de modo a ultrapassar os obstáculos que os formandos sentem no contacto com a realidade profissional e que atribuem preferencialmente à inadequação da formação teórica e/ou das formas pelas quais é transmitida (ESTRELA, 2002; RODRIGUES, 1999).

A conceção de estratégias de formação dos mentores e o planeamento e desenvolvimento das atividades durante e entre as sessões presenciais enquadraram-se na terceira perspetiva atrás referida. Trata-se, em suma, de rever o papel atribuído aos formandos nos processos de formação contínua, desenhando-se um novo perfil de professor como sujeito e objeto da formação, "agente corresponsável do sistema de formação contínua, favorecendo assim a emergência e consolidação da sua autonomia pessoal" (ESTRELA et al., 2005 p. 137). Este perfil corresponde a uma conceção de professor enquanto profissional que investe no seu desenvolvimento e reinveste na escola e na sala de aula as aprendizagens desenvolvidas na formação, através de um trabalho colaborativo interpares.

\section{Conceção e orientação do programa de formação}

Sendo o desenvolvimento profissional docente o objetivo último da formação, tornou-se necessário evidenciar as formas pelas quais o processo supervisivo dos mentores e as atividades dos professores em período probatório poderiam concorrer para esse desenvolvimento. Nesse sentido, desde o início houve a preocupação de estabelecer as relações entre desenvolvimento profissional, supervisão e ato de ensinar, nas suas diferentes dimensões. 
0 termo desenvolvimento profissional surge associado à perspetiva desenvolvimentista da formação contínua e diretamente relacionado com a natureza continuada da carreira dos professores e com a sua aprendizagem ao longo da vida (HOLLY, 1989). Em 1990, Fullan (1990), definia o conceito a partir dos objetivos, afirmando que este inclui "qualquer atividade ou processo que procure melhorar competências, atitudes, compreensão ou ação em papéis atuais ou futuros" (p. 3). Por sua vez, Day (2001 p. 18) analisa o conceito a partir do tipo de atividades que engloba:

0 conceito de desenvolvimento profissional (...) representa aquilo que outros denominaram "visão alargada da aprendizagem profissional" (LIEBERMAN, 1996). Inclui, por isso, quer a aprendizagem eminentemente pessoal, sem qualquer tipo de orientação, a partir da experiência (através da qual a maioria dos professores aprende a sobreviver, a desenvolver competências e a crescer profissionalmente nas salas de aula e nas escolas), quer as oportunidades informais de desenvolvimento profissional vividas na escola, quer ainda as mais formais oportunidades de aprendizagem "acelerada", disponiveis através de treino e de formação contínua, externa e internamente organizadas.

Nóvoa (2002 p. 72), porém, adverte para a enganadora sedução do termo, já que este apela ao surgimento de mudanças no plano pessoal, coletivo e organizacional, mas a "inflação retórica à volta do conceito" não tem contribuído para a modificação da posição e do habitus dos professores. Nos processos de desenvolvimento profissional, este autor salienta a necessidade de investir: i) na pessoa do professor; ii) no contexto da escola; iii) e na dimensão coletiva da classe profissional. Para favorecer o desenvolvimento profissional, é necessário que os processos de formação e os modelos de supervisão atendam às características e dinâmicas pessoais, tendo em conta a forma de ensinar e de aprender de cada docente; é necessário ainda que se articulem com os projetos de inovação curricular na escola, enraizando-se nas dinâmicas das equipas pedagógicas e da organização escolar. De modo a "contribuir para reforçar as vivências coletivas da profissão" (Nóvoa, 2002 p. 44), torna-se necessário reforçar os processos de supervisão interpares, através de práticas dialógicas e colaborativas.

Alarcão e Roldão (2008) relacionam também a construção e desenvolvimento profissional com a supervisão, salientando a necessidade de autoimplicação dos participantes, a referenciação à ação docente e aos saberes constituídos e a sua característica de permanente reconstrução. A referenciação à ação docente exige, por sua vez, uma atitude de permanente análise e questionamento do real através da observação de si e dos outros, da reflexão e do feedback, processos associados à autossupervisão ou à supervisão interpares. 
Estas autoras salientam, porém, que os estudos sobre formação contínua mostram que parece vigorar na classe docente a crença na espontaneidade do desenvolvimento profissional, o qual decorreria automaticamente do exercício da profissão e sem ligação com os processos formativos, percecionados como exteriores a esse desenvolvimento. Ao invés, as autoras salientam que os processos bem conseguidos de desenvolvimento profissional combinam "o envolvimento coletivo na formação, a centralização na análise reflexiva sobre as práticas e o apoio de formadores ou investigadores" (ALARCÃO; ROLDÃO, 2008 p. 34).

Estas três dimensões constituíram a trave-mestra da conceção do programa de formação dos mentores, estando na origem dos seus princípios organizadores:

- a formação constitui-se como suporte e acompanhamento do processo de supervisão desenvolvido pelos mentores com os professores nas escolas, proporcionando o debate e a análise das situações de supervisão planeadas e/ou vividas e não como preparação prévia para o desempenho de um novo papel;

- a formação organiza-se de forma a acompanhar sequencialmente as várias fases do período probatório, motivo pelo qual a temática central de cada sessão corresponde ao trabalho a desenvolver pelos mentores e professores em período probatório nas respetivas escolas e redefine-se e a partir das preocupações e dificuldades dos mentores e do feedback sobre o trabalho realizado com os professores em período probatório;

- a formação implica o questionamento e problematização das situações e ações de docência, razão por que deve organizar-se, ela própria, a partir de questões orientadoras às quais formadores e mentores-formandos procuram responder em cada sessão;

- a formação desenvolve-se com grupos de mentores de escolas da mesma região, os quais podem constituir uma rede regional de suporte, colaboração e apoio mútuo. Para tal, é necessário que as sessões de formação se desenvolvam com base em estratégias de colaboração interpares.

- a formação deverá ter repercussões no desenvolvimento organizacional das escolas, o que pressupõe não apenas a divulgação, discussão e análise do trabalho desenvolvido por mentores e professores em periodo probatório nos órgãos centrais e intermédios da escola, mas também a divulgação e reflexão sobre as principais questões abordadas na formação.

Em síntese, o Programa de Supervisão, Acompanhamento e Avaliação do período Probatório dos Professores orientou-se para o desenvolvimento profissional docente (dos mentores e dos professores em período probatório) e centrou-se no conhecimento profissional necessário à ação de ensinar (operacionalização das dimensões da função docente e avaliação do desempenho dessa função). 
Em consequência, na Oficina de Formação para Professores Mentores definiu-se a função de ensinar e o conhecimento docente como objeto principal do processo supervisivo e o desenvolvimento profissional docente como objetivo dessa supervisão. Neste sentido, supervisão e ação docente foram os dois eixos centrais da formação, procurando estabelecer entre eles uma ligação conceptual mas também operativa, que suportasse efetivamente o papel supervisivo dos mentores junto dos professores em periodo probatório.

$\mathrm{Na}$ figura seguinte sintetizamos a articulação entre os eixos centrais definidos para o Período Probatório, os temas abordados na formação dos mentores e a supervisão que estes desenvolviam, entretanto, nas suas escolas.

Figura 1 - Orientação do Programa e articulação da formação com a supervisão.

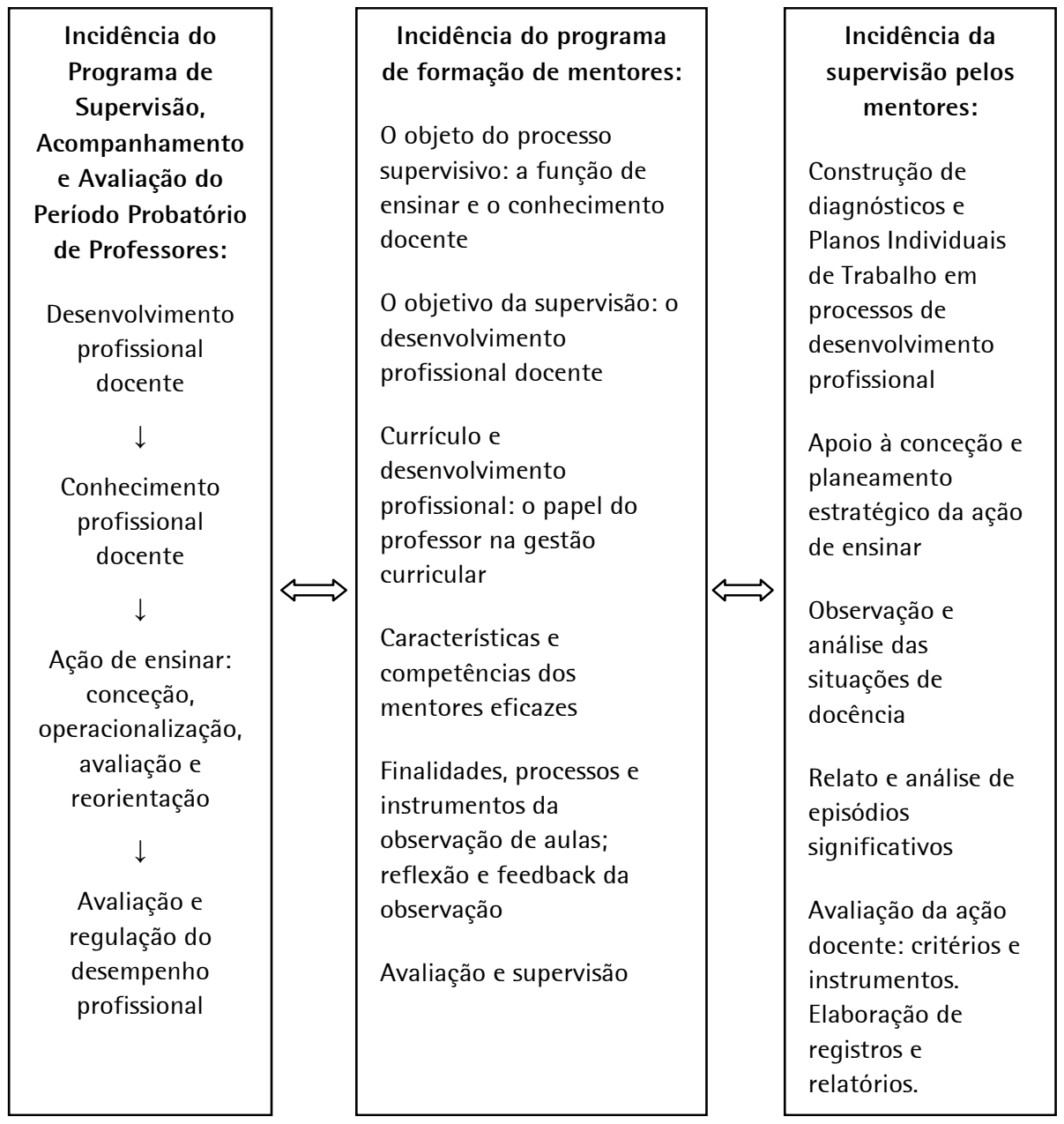

Fonte: A autora (2012). 
Tendo em conta este desenho geral, as sessões de formação dos mentores foram planeadas por temas-chave, os quais se organizaram a partir de questões orientadoras. A formulação de questões orientadoras para cada sessão criou um rumo de orientação muito claro, favorecendo o planeamento estratégico para atingir os objetivos. Para além disso, contribuiu para a definição precisa dos resultados esperados, uma vez que, no final de cada sessão, se esperava que os mentores tivessem encontrado a resposta para a pergunta de partida.

Se todo o conhecimento tem origem na formulação de perguntas, organizar a formação a partir de questões e orientá-la para a procura de respostas é ajudar a construir quadros de referência estáveis que permitam ler as situações e fenómenos do quotidiano educativo. 0 quadro seguinte mostra a relação entre as questões orientadoras e os objetivos específicos de cada sessão.

Quadro 1 - Organização das sessões de formação

\begin{tabular}{|c|c|c|}
\hline Tema/sessão & Questões orientadoras & Objetivos \\
\hline $\begin{array}{l}\text { 1. Construção de } \\
\text { planos individu- } \\
\text { ais de trabalho e } \\
\text { Desenvolvimento } \\
\text { Profissional }\end{array}$ & $\begin{array}{l}\text { Em que consiste e como se opera- } \\
\text { cionaliza um processo de desen- } \\
\text { volvimento pessoal e profissionat? } \\
\text { Como se supervisiona, para me- } \\
\text { Ihorar, um processo de desenvol- } \\
\text { vimento profissional? } \\
\text { Que papel desempenha o plano } \\
\text { individual de trabalho do professor } \\
\text { nesse processo? }\end{array}$ & $\begin{array}{l}\text { Clarificar de que modo o Periodo } \\
\text { Probatório constitui um periodo de } \\
\text { tuinuacâaitmento profissional - cujo } \\
\text { resultado se avalia, para melhorar a } \\
\text { progressão seguinte. } \\
\text { Identificar a necessidade de construir } \\
\text { desde o início um dispositivo proces- } \\
\text { sual acordado entre o mentor e o PPP } \\
\text { Estabelecer o princípio de que o } \\
\text { ponto de partida se apoia sempre } \\
\text { na experiência prévia e no saber do } \\
\text { PPP, através do diagnóstico dos seus } \\
\text { pontos fortes e fracos, necessidades e } \\
\text { potencialidades, tal como ele próprio } \\
\text { as identifica. } \\
\text { Caracterizar o papel do mentor no } \\
\text { processo, alimentando-o e orientan- } \\
\text { do-o, enriquecendo o saber e apoian- } \\
\text { do interactivamente a melhoria da } \\
\text { ação profissional. }\end{array}$ \\
\hline
\end{tabular}

(Continuação) 
(Continuação)

\begin{tabular}{|c|c|c|}
\hline $\begin{array}{l}\text { 2. Planeamento e } \\
\text { conceção da ação } \\
\text { de ensinar }\end{array}$ & $\begin{array}{l}\text { Que aspetos considerar na con- } \\
\text { ceção e planeamento da ação } \\
\text { docente? } \\
\text { Que procedimentos supervisivos } \\
\text { adotar para a sua melhoria? }\end{array}$ & $\begin{array}{l}\text { Enquadrar a conceção e planeamen- } \\
\text { to da ação no processo de gestão } \\
\text { curricular. } \\
\text { Identificar as operações realizadas } \\
\text { para conceber e planificar a ação } \\
\text { de ensinar. } \\
\text { Relacionar o papel do professor na } \\
\text { gestão do currículo e na conceção } \\
\text { estratégica da ação com a profis- } \\
\text { sionalidade docente e o desenvolvi- } \\
\text { mento profissional. } \\
\text { Desenvolver competências de apoio su- } \\
\text { pervisisvo no processo de planeamento. }\end{array}$ \\
\hline $\begin{array}{l}\text { 3. Análise e discus- } \\
\text { são das situações de } \\
\text { docência }\end{array}$ & $\begin{array}{l}\text { Que aspetos ter em conta no de- } \\
\text { senvolvimento da ação? } \\
\text { Que procedimentos supervisivos } \\
\text { adotar para a sua melhoria? }\end{array}$ & $\begin{array}{l}\text { Desenvolver competências supervi- } \\
\text { sivas dos mentores. } \\
\text { Apresentar a supervisão centrada na sala } \\
\text { de aula como processo faseado e cíclico. } \\
\text { Propor um conjunto de práticas } \\
\text { para diferentes fases do processo } \\
\text { supervisivo. }\end{array}$ \\
\hline $\begin{array}{l}\text { 4. Avaliação e re- } \\
\text { gulação do desem- } \\
\text { penho profissional }\end{array}$ & $\begin{array}{l}\text { Como definir critérios de avalia- } \\
\text { ção para diferentes dimensões de } \\
\text { desempenho docente? } \\
\text { Que relação entre supervisão e } \\
\text { avaliação? } \\
\text { Como promover o desenvolvi- } \\
\text { mento profissional através da su- } \\
\text { pervisão e da avaliação? Com que } \\
\text { critérios e com que indicadores? }\end{array}$ & $\begin{array}{l}\text { Reconhecer a multidimensionalidade } \\
\text { associada ao conceito de avaliação. } \\
\text { Relacionar o processo de avaliação } \\
\text { com os conceitos de critério, indi- } \\
\text { cador e evidência. } \\
\text { Identificar o papel dos processos de } \\
\text { supervisão e de avaliação no desen- } \\
\text { volvimento profissional docente. }\end{array}$ \\
\hline $\begin{array}{l}\text { 5. Supervisão e ava- } \\
\text { liação: construção } \\
\text { de registos e rela- } \\
\text { tórios }\end{array}$ & $\begin{array}{l}\text { Em que medida pode o relato } \\
\text { funcionar como instrumento de } \\
\text { desenvolvimento profissional? } \\
\text { Como construir relatórios que } \\
\text { fomentem e traduzam o processo } \\
\text { de desenvolvimento profissional } \\
\text { no contextos de um processo de } \\
\text { supervisão? }\end{array}$ & $\begin{array}{l}\text { Sensibilizar para a importância do } \\
\text { uso de registos. } \\
\text { Enquadrar o uso de registos nas } \\
\text { práticas de supervisão e avaliação. } \\
\text { Sugerir procedimentos de elaboração } \\
\text { de relatórios. }\end{array}$ \\
\hline
\end{tabular}

Fonte : A autora (2012).

Estando as questões orientadoras da formação em estreita ligação com as várias fases do processo de supervisão a desenvolver e este com a ação do professor em período probatório, tornou-se possivel delinear estratégias que conjugassem a 
abordagem teórica de conceitos, o apoio aos professores em período probatório e análise das práticas desses professores, além dos problemas e dificuldades surgidos entretanto no processos de supervisão dos mentores. A análise conjunta desses problemas, nas sessões de formação, em articulação com a abordagem teórica favoreceu ainda a procura e a partilha de soluções inovadoras e criativas para situações imprevistas, por vezes potencialmente conflituosas, outras vezes de mera rejeição passiva por parte dos professores em periodo probatório.

Foi possivel, assim, delinear um processo formativo que previa etapas bem definidas e formas de monitorização quer da supervisão, quer da ação pedagógica, com base num trabalho colaborativo entre formadores e mentores que incluiu a análise, desconstrução e reconstrução de conceções e crenças, criando um ambiente facilitador da comunicação e orientando o processo para a consecução de um objetivo comum.

\section{Planeamento estratégico das atividades de formação}

Se toda a educação formal assenta na dialética de separação e articulação entre teoria e prática, como afirma Malglaive (1997), é possivel afirmar que o sistema escolar privilegia a separação, enquanto a formação profissional (e, nesta, a formação contínua) privilegia a articulação, uma vez que tem como marco de referência não apenas a evolução científica e tecnológica, mas também as transformações e necessidades pessoais e dos contextos laborais em concreto. 0 campo do trabalho, mais do que o lugar em que se aplicam conhecimentos, técnicas e atitudes adquiridas na formação, assume-se como o espaço onde se transformam ou produzem saberes e identidades, construídos ou reconstruídos através da experiência e da análise e reflexão sobre ela.

Na maior parte dos dispositivos criados para a formação contínua, o que se pretende é assegurar que esta sirva, efetivamente, a atividade profissional. No caso dos professores, a questão põe-se com maior pertinência, já que, por desenvolverem o seu trabalho num contexto escolar, há maior tendência (por parte de formadores e de formandos) para fazer passar para a formação características curriculares e pedagógicas próprias da educação de crianças e jovens e, neste sentido, para distanciar o ensino/aprendizagem das situações concretas de utilização dos conhecimentos e competências. Por outro lado, o hábito (mais uma vez, tanto dos formadores como dos formandos) de lidar com conceitos e teorias e de usar o discurso como forma de persuasão contribui também para fazer enveredar a formação dos professores por caminhos mais abstratos e mais desligados da realidade profissional. Como afirma Rodrigues (1999 p. 64), enquanto a formação profissional de adultos se preocupa com a articulação entre formação e trabalho, "a formação de professores permanece, nas suas realizações mais comuns e institucionais, presa a conceções individualistas e académicas, como se receasse ser contaminada pela prática e pela experiência". 
As consequências deste fenómeno são notoriamente conhecidas: por um lado um discurso sobre o real contaminado pelos vocábulos e referências teóricas mais em moda, disseminados em ações de formação avulsas, que se afastam da realidade das escolas e das necessidades dos professores; por outro uma prática que não tem qualquer relação com esses discurso e se aprende e desenvolve à volta de si mesma e de esquemas de ação construídos quase exclusivamente a partir da experiência.

De facto, a tradição da primazia da teoria sobre a prática (e, por conseguinte, a noção de prática como aplicação da teoria), na formação de professores, teve como efeito a desvalorização dessa mesma teoria quando confrontada com o real e, consequentemente, a construção de uma prática interpretada tendencialmente à margem dos quadros de referência conceptual. (ESTRELA; ESTRELA, 2001).

Por outro lado, as correntes que investem a prática de todo o potencial formativo, partindo da análise da natureza da competência profissional construída em situação - através de uma ação refletida na experiência e de um saber globalizante desenvolvido também pela experiência - em última instância podem conduzir a práticas artesanais no processo de profissionalização e, no limite, à negação da necessidade de formação profissional de professores.

Em 2005, Estrela et al. verificaram que a maior parte dos estudos realizados em Portugal sobre Formação Contínua de Professores (1990-2004) apresentam resultados consensuais no que respeita à opinião dos formandos-professores sobre os processos através dos quais essa formação se deverá realizar, nomeadamente sobre as estratégias de formação. Os formandos-professores inquiridos nesses estudos valorizam ...

"estratégias formativas centradas no trabalho colaborativo e
na reflexão sobre as suas práticas, aproximadas à conceção de
professor como profissional reflexivo. 0 discurso dos profis-
sionais é legitimado à luz da literatura da especialidade, com
referências concretas a modelos preconizados por Zeicnher,
Schon e Demailly." (ESTRELA et al., 2005 p. 127).

Nos estudos analisados nessa resenha, propõem-se modalidades de formação centradas nos contextos escolares e nas práticas profissionais, utilizando estratégias que levem os professores a refletir, conjuntamente com os formadores, sobre os problemas concretos do quotidiano docente e sobre as necessidades de formação dai decorrentes e produzindo materiais curriculares pertinentes à prática. Em termos gerais, sugere-se 0 recurso a metodologias ativas que promovam a autoformação em contexto profissional.

Há, assim, uma clara incidência em processos colaborativos e reflexivos que, no entanto, parecem corresponder mais a um discurso sobre um ideal de formação do que a processos concretos e vivenciados. Profundamente disseminado 
entre os formadores e a classe docente, o conceito de reflexão sobre a prática parece obter um inusitado consenso que, na maior parte dos casos, obscurece o sentido inicial que DEWEY $(1933$, apud ALARCÃO, 1991) e, mais tarde, Schon (1987) Ihe conferiram.

\section{Como afirma Estrela (2002 p. 25):}

"a prática reflexiva constitui atualmente uma disposição profissional genérica que os programas de formação contemplam com maior ou menor convicção" e, sob a mesma designação surgem conceitos essencialmente diferentes de reflexão e prática reflexiva, os quais apontam para conceções de professor e de formação com fracas semelhanças entre si, quando não totalmente opostas. Nesse sentido, mais do que novos modelos específicos de formação, a generalização da noção de reflexão tem dado origem a novas retóricas, uma vez que são escassas as evidências empíricas sobre os seus efeitos na ação concreta do professor na sala de aula e na escola ou nos resultados dessa ação".

Já em 1997, esta autora sublinhara que "o slogan da reflexividade" pode ter efeitos perversos porque, ao pôr em causa a racionalidade técnica, atinge os resultados da própria investigação educacional e, nesse processo, o conhecimento cientificamente fundamentado sobre a profissão, que representa uma forma de a revalorizar e a autonomizar. Fazia notar ainda que a conceção de professor como técnico não implica, forçosamente, a desvalorização da capacidade reflexiva e inovadora deste, porque um bom técnico não se limita a aplicar passivamente conhecimentos e/ou as suas aplicações: pelo contrário, analisa situações concretas e conjuga os conhecimentos de forma criativa, de modo a poder dar resposta adequada a essas situações. No mesmo sentido se pronuncia Day (2001), afirmando que a distinção entre prático reflexivo e técnico competente nem sempre é útil, porque os bons professores são técnicos competentes que refletem não apenas sobre as estratégias de ensino e os seus efeitos, mas também sobre questões mais latas relativas ao ensino. Os problemas surgem, realmente, quando técnica e reflexão se separam.

Em sintese, se a reflexão sobre a prática e a articulação entre esta e a teoria devem ser eixos orientadores do planeamento da formação, é necessário que não se restrinjam a uma retórica de intencionalidades difusas, com escassas repercussões na seleção e criação das estratégias e atividades a desenvolver e dos materiais a utilizar e a produzir pelos formandos. Por outro lado, a coerência entre os processos formativos e os processos a desenvolver na docência surge como uma condição sine qua non para a desmistificação das representações de irrealismo e impraticabilidade usualmente atribuidas pelos docentes às propostas apresentadas na formação. 
No programa de formação para os mentores dos professores em Período Probatório, o planeamento de cada sessão, bem como a seleção e/ou construção de materiais foram realizados por um dos elementos da equipa e depois sujeitos a discussão e melhoramento em comum. Assim, para cada sessão, a equipa de formadores concebeu e planeou

- um conjunto de atividades orientadas para a:

- a análise do trabalho realizado durante o mês anterior e dos seus resultados;

- a exploração e aprofundamento dos conceitos-chave de cada sessão;

- a preparação do trabalho a desenvolver no mês seguinte, a partir da exploração dos conceitos-chave;

- um conjunto de materiais para análise e discussão dos temas focados;

- a definição dos outputs de cada sessão.

Este planeamento comum foi depois adequado às caracteristicas específicas do grupo de mentores de cada região.

Para cada sessão elaborou-se ainda uma brochura, a qual continha as questões orientadoras, os objetivos, os conceitos-chave, a descrição das atividades, os textos de apoio e restantes materiais. As brochuras foram publicadas pela Universidade de Aveiro e disponibilizadas em formato digital no site do Ministério da Educação.

A análise da descrição das atividades planeadas mostra que estas incidem em:

- discussões em grande grupo sobre os conceitos-chave de cada sessão, numa primeira fase baseadas em conhecimentos e experiências anteriores e, numa segunda fase. nos materiais de apoio fornecidos;

- análise e/ou enriquecimento de guiões e esquemas fornecidos, em pequenos grupos, com posterior apresentação ao grande grupo;

- construção em pequenos grupos de guiões e de esquemas orientadores para os supervisores e para os professores em periodo probatório;

- sínteses e sistematizações em grande grupo do resultado dos produtos realizados em pequenos grupos, na formação, ou individualmente, nas escolas;

- apresentações, análise e debate sobre as experiências de supervisão vivenciadas e os episódios mais significativos desse processo;

- apresentações, análise e debate sobre as formas e instrumentos de observação de aulas e o tipo de feedback utilizado pelos mentores;

- análise, comparação de resultados e debate sobre processos e critérios de avaliação de desempenho.

Estas atividades inserem-se numa organização estratégica da ação formativa que pretende fazer aprender através da construção pelos formandos de esquemas 
de interpretação estruturantes dos conteúdos abordados e, em simultâneo, da produção por eles próprios de instrumentos de planeamento da ação e de recolha e análise de dados que Ihes permitam acionar esses esquemas e mobilizá-los para as situações supervisivas e de apoio à docência dos professores em periodo probatório.

Com efeito, nos planos de qualquer das cinco sessões, é possivel identificar uma linha de atuação que perspetiva a sequencialização e exploração estratégica destas atividades com vista à consecução dos objetivos (ROLDÃO, 2009). Este tipo de planeamento da ação formativa tem por trás uma conceção de formação que se aproxima da conceção de ensino como "ação intencional dirigida a promover a aprendizagem em alguém" (ROLDÃO, 2009 p. 56), conceção que foi amplamente analisada, discutida, reorganizada e formalizada durante a formação. Deste modo, a perspetiva de formação e as experiências vividas pelos formandos-mentores durante esse processo tornam-se coerentes com a perspetiva de ensino defendida nessa mesma formação. Em simultâneo, a realização dessas atividades e a explicitação da sua organização e finalização face aos objetivos, clarificam de forma realista a possibilidade de pôr em prática dispositivos deste tipo, não permitindo que se instale nos formandos a ideia (tão habitual que parece um dado adquirido) de que a formação transmite modelos ideais e irrealizáveis na prática letiva quotidiana.

Por isso, procurou-se que a formação abordasse em concreto os aspetos metodológicos da supervisão e do ensino, bem como procedimentos de natureza técnica, como a construção e uso de instrumentos de recolha e análise de dados. Assim, nas atividades propostas durante a formação, os mentores construíram ou reconstruíram em conjunto materiais a utilizar na supervisão, através dos quais recolheram evidências do processo desenvolvido. No espaço que mediava entre as sessões, era pedido aos mentores ou, através destes, aos professores em período probatório (PPP) que utilizassem esses materiais (questionários, guiões, grelhas de planeamento ou observação, relatos de vários tipos), apresentando-os na sessão seguinte. Estes eram depois objeto de análise e feedback por parte dos formadores, tornando possivel um efetivo acompanhamento e apoio não apenas aos processos desenvolvidos nas escolas pelos mentores, mas também, ainda que de forma indireta, aos processos desenvolvidos na sala de aula pelos professores em período probatório (quadro 2).

Esta vertente mais técnica e/ou procedimental facilitou a reflexão dos mentores sobre a sua própria prática de supervisão e sobre o apoio por eles dado à reflexão dos professores em período probatório sobre a sua prática de ensino. Mais do que isso, a construção, utilização, análise e feed-back sobre a utilização desses instrumentos permitiu aos mentores uma real participação e envolvimento não apenas nas atividades propostas na formação, mas também na adequação destas às necessidades concretas, reorientando o sentido da formação, quando necessário. 
Quadro 2 - Produtos trabalhados durante a formação

\begin{tabular}{|c|c|c|}
\hline Tema/sessão & Produtos a apresentar à sessão seguinte & \multirow{6}{*}{$\begin{array}{l}\text { Feedback } \\
\text { por região }\end{array}$} \\
\hline $\begin{array}{l}\text { 1. Construção de planos indivi- } \\
\text { duais de trabalho e desenvolvi- } \\
\text { mento profissional }\end{array}$ & $\begin{array}{l}\text { Realização do diagnóstico inicial (uti- } \\
\text { lização do questionário orientador da } \\
\text { sessão de supervisão Mentor/Professor). } \\
\text { Elaboração do Plano individual de tra- } \\
\text { balho pelo PPP. }\end{array}$ & \\
\hline $\begin{array}{l}\text { 2. Planeamento e conceção da ação } \\
\text { de ensinar }\end{array}$ & $\begin{array}{l}\text { Síntese do Plano de Intervenção do } \\
\text { PPP com a turma } \\
\text { Planificação de uma unidade di- } \\
\text { dática. }\end{array}$ & \\
\hline $\begin{array}{l}\text { 3. Análise e discussão das situações } \\
\text { de docência }\end{array}$ & $\begin{array}{l}\text { Descrição de uma observação de } \\
\text { aula pelo mentor e apresentação do } \\
\text { instrumento utilizado. }\end{array}$ & \\
\hline $\begin{array}{l}\text { 4. Avaliação e regulação do desem- } \\
\text { penho profissional }\end{array}$ & $\begin{array}{l}\text { Relatório de desempenho do PPP de } \\
\text { acordo com as dimensões do ato de } \\
\text { ensinar antes trabalhadas. }\end{array}$ & \\
\hline $\begin{array}{l}\text { 5. Supervisão e avaliação: constru- } \\
\text { ção de registos e relatórios }\end{array}$ & $\begin{array}{l}\text { Relato de um episódio de supervisão. } \\
\text { Reflexão sobre a formação. }\end{array}$ & \\
\hline
\end{tabular}

Fonte: A autora (2012).

Assim, se coube aos formadores a definição da intencionalidade da formação e a conceção das estratégias formativas a desenvolver, foi aos formandos-mentores que coube a a responsabilidade de gerar conhecimento prático e estratégico sustentado pela reflexão teórica. Este papel dos professores como "agentes [...] e teorizadores de uma prática, mediante a produção, validação e circulação do seu conhecimento específico" (ROLDÃO, 2010a, p. 39) parece-nos ser hoje condição necessária para o desenvolvimento profissional individual e para a afirmação da profissionalidade da classe.

Se perspetivada nesta direção, a formação contínua pode tornar-se um meio de emancipação profissional, favorecendo não apenas a reflexão sobre a prática, mas sobretudo a sua teorização. Sem esta teorização, a ação corre o risco de se perpetuar como o uso de um conjunto de técnicas mais ou menos eficazes e a reflexão pende definitivamente para "a emissão de opiniões pessoais sobre os problemas do ensino [...]", perdendo-se em discursos autolegitimadores "que hipotecam o desenvolvimento profissional" (SOUSA, 2010 p. 121).

Deste modo, no final da formação dos mentores, existia um considerável acervo de produtos realizados pelos intervenientes durante o processo de mentoria e trabalhados durante a formação: 
- Planos individuais de trabalho e planificações da intervenção pedagógica realizados pelos professores em período probatório, com a colaboração dos professores mentores;

- Planeamento e descrições do processo de ensino pelos professores em período probatório e produtos realizados pelos alunos durante esse período;

- Planeamento do processo supervisão, registos de reuniões entre mentores e professores em período probatório, registos de observação de aulas, relatos de episódios críticos de supervisão e reflexões finais sobre o processo de formação.

A análise de alguns destes produtos, apresentada nos artigos seguintes, permitirá conhecer o grau em que foram conseguidas as intencionalidades teóricas e metodológicas aqui enunciadas.

\section{Referências}

ALARCÃO, I. Reflexão crítica sobre o pensamento de D. Schön e os programas de formação de professores. Porto: Porto, 1991. (Coleção Cadernos CIDInE, n. 1).

ALARCÃO, I.; ROLDÃO, M. C. Supervisão: um contexto de desenvolvimento profissional dos professores. Mangualde: Edições Pedagogo, 2008.

BROWN, S.; MCINTYRE, D. Making sense of teaching. Buckingham: Open University Press, 1993.

CARROLO, C. Formação e identidade profissional dos professores. In: ESTRELA, M. T. (Org.). Viver e construir a profissão docente. Porto: Porto, 1997.

CONTRERAS DOMINGO, J. A autonomia da classe docente. Porto: Porto, 2003.

DANIELSON, C. Melhorar a prática profissional: um quadro de referência para a docência. Lisboa: Ministério da Educação, 2010.

DAY, C. Desenvolvimento profissional de professores: os desafios da aprendizagem permanente. Porto: Porto, 2001.

ERAUT, M. Inservice teacher education. In: DUNKIN, M. J. (Ed.) The international encyclopedia of teachers and teaching education. Oxford: Pergamon Press, 1985.

ESTRELA, A. et al. A investigação sobre a formação contínua de professores em Portugal (1990-2004). Investigar em educação: Revista da Sociedade Portuguesa de Ciências da Educação, Lisboa, n. 4, p. 107-148, 2005. 
ESTRELA, M. T. Modelos de formação de professores e seus pressupostos conceptuais. Revista de Educação, v. 11, n. 1, p. 17-20, 2002.

ESTRELA, M. T.; ESTRELA, A. IRA: investigação, reflexão, acção e formação de professores. Porto: Porto, 2001.

FERRY, G. Le trajet de la formation. Paris: Presses Universitaires Françaises, 1987.

FULLAN, M. Staff development innovation and institutional development. In: BRUCE, J. (Ed.). School culture through staff development. Virginia: ASCD, 1990. p. 3-25.

FULLER, F.; BROWN, O. Becoming a teacher. In: RYAN, K. (Ed.). Teacher education: seventy-fourth yearbook of the National Society for the Study of Education. Chicago: University of Chicago Press, 1975.

GIMENO SÁCRISTÁN, J. Consciência e acção sobre a prática como libertação profissional dos professores. In: NÓVOA, A. (Org.). Profissão: professor. Porto: Porto Ed., 1991.

GONÇALVES, J. A. A carreira dos professores do ensino primário. In: NÓVA, A. (Org.). Vidas de professores. Porto: Porto Ed., 1999.

HARGREAVES, D. A common-sense model of the professional development of teachers. In: ELLIOT, J. (Ed.). Reconstructing teacher education. London: The Falmer Press, 1993.

HOLLY, M. L.; MCLOUGHIN, C. S. Perspectives on teacher professional development. London: The Falmer Press, 1989.

HOYLE, E. Professionalization and desprofessionalization in education. In: HOYLE, E.; MEGANY, J. (Eds). World yearbook of education: professional development of teachers. London: Kogan Page, 1980. p. 42-54.

HUBERMAN, M. 0 ciclo de vida profissional dos professores. In: NÓVA, A. (Org.). Vidas de professores. Porto: Porto, 1999.

KILLEVY, M.; MURPHY, R. National pilot project on teacher induction. Dublin: Department of Education and Science, 2006.

MALGLAIVE, G. Formação e saberes profissionais: entre a teoria e a prática. In: CANÁRIO, R. (Org.) Formação e situações de trabalho. Porto: Porto Ed, 1997. 
MARCELO GARCÍA, C. Formação de Professores: para uma mudança educativa. Porto: Porto, 1999.

NÓVOA, A. Formação de professores e trabalho pedagógico. Lisboa: Educa, 2002.

RODRIGUES, A. Construção de planos individuais de trabalho e desenvolvimento profissional. Aveiro: Universidade de Aveiro, 2010a. (Colecção Situações de Formação n. 1).

Ensinar e aprender: o saber e o agir distintivos do profissional docente. In: ENS, R.; BEHRENS, M. (Org.). Formação do professor: profissionalidade, pesquisa e cultura escolar. Curitiba: Champagnat Ed., $2010 b$.

. Estratégias de ensino: o saber e o agir do professor. Gaia: Fundação Manuel Leão, 2009.

Metodologia de análise de necessidades de formação na formação profissional contínua de professores. 1999. $152 \mathrm{f}$. Tese (Doutorado)-Faculdade de Educação, Universidade de Lisboa, Lisboa, 1999.

SCHON, D. A. Educating the reflective practitioner. San Francisco: Jossey-Bass Publishers, 1987.

SHULMAN, L. S. Case method in teacher education. New York: Columbia University, 1992.

SILVA, M. C. M. 0 primeiro ano da docência: o choque com a realidade. In: ESTRELA, M. T. Viver e construir a função docente. Lisboa: Porto, 1997, p. 51-80.

SOUSA, F. Diferenciação curricular e deliberação docente. Porto: Porto, 2010.

WOODS, P. Investigar a arte de ensinar. Porto: Porto Editora, 1999.

ZEICHNER, K. A formação reflexiva de professores: ideias e práticas. Lisboa: Educa, 1993.

ZEICHNER, K. Alternatives paradigms in teacher education. Journal of Teacher Education, Washington, v. 34, n. 3, p. 3-9, 1983.

Recebido em: 12/04/2012

Aceito para publicação em: 17/08/2012 